\title{
Carbohydrate conundrum: Why Canadians cannot fit into their skinny genes
}

\section{T. Dylan Olver and Graeme W.R. Thomas}

\section{University of Western Ontario}

\section{The Numbers}

Between 1979 and 2004, adult Canadian obesity rates increased 67\%. ${ }^{1}$ Accordingly, from 1999-2009 agestandardized prevalence of type II diabetes rose $70 \%{ }^{2}$ In light of these dramatic increases, the validity of current diet recommendations warrants questioning.

The Acceptable Macronutrient Distribution Range (AMDR) recommendations contained within the North American Dietary Reference Intake (DRI) report are thought to represent the nutrient intake required to reduce the incidence of chronic disease. ${ }^{3}$ Established at $45-65 \%$ of total daily energy intake, the AMDR for carbohydrate amounts to $255-365 \mathrm{~g} /$ day on a typical $2250 \mathrm{kcal}$ diet. Considering the human body can produce sufficient carbohydrates to meet health requirements via hepatic gluconeogenesis ${ }^{3,4}$ and carbohydrate overconsumption has been linked to hyperglycemia and hyperinsulinemia ${ }^{3}$ one must question the claim that the AMDR reduces risk for chronic disease. If the AMDR for carbohydrate does not reflect physiological need, it is plausible that excess carbohydrate intake promoted by the AMDR is a contributing factor to the ongoing obesity and type II diabetes epidemics.

\section{Cause for Questionning}

Support for this hypothesis is advanced in part through a second nutrient recommendation contained within the DRI report: the Recommended Dietary Allowance (RDA). The RDA for carbohydrate is established at $130 \mathrm{~g} /$ day and corresponds to the dietary intake level considered adequate to meet the requirements of $\sim 98 \%$ of the healthy population. $^{3}$

Adult Canadian carbohydrate consumption is currently estimated at $\sim 300 \mathrm{~g} / \mathrm{day}^{5}{ }^{5}$ an amount consistent with the AMDR recommendation. However, as obesity rates continue to increase, the question must be asked: Are the additional $>150 \mathrm{~g}$ of ingested carbohydrate (estimated intake - RDA) protecting Canadians from chronic disease as the AMDR suggests? The DRI report is unable to form clinically relevant conclusions on the matter and cites evidence from traditional populations and experimental studies that demonstrate humans can thrive on low-carbohydrate diets with no adverse effects on health or longevity. ${ }^{3}$ Further, carbohydrate consumption is theoretically non-essential as the liver can synthesize sufficient glucose to sustain health ( $240 \mathrm{~g} /$ day), provided the diet consists of adequate amounts of fats and protein., ${ }^{3,4}$

Given the modest amount of carbohydrate necessary to meet health requirements (RDA; $130 \mathrm{~g} /$ day), coupled with evidence that this amount can be produced/consumed and sustained practically without harm, is it conceivable that current carbohydrate intake may lead to metabolic complications? The DRI acknowledges such risks by explaining that chronically high-carbohydrate diets may lead to hyperinsulinemia, hyperglycemia and insulin resistance/type II diabetes. ${ }^{3}$

\section{A Refined Society?}

In addition to the hyperinsulinemic potential of a highcarbohydrate diet, the progressive milling and refining of grain (i.e., whole grain $<$ cracked grain $<$ coarse flour $<$ fine flour) produces a stepwise increase in insulin secretion. ${ }^{6}$ With refined breads, pastas, cereals and sweetened beverages commonplace today, ${ }^{5}$ the associated increase in insulin stimulation ${ }^{3,7}$ may result in heightened stress on the pancreas and liver.

Particularly troublesome is how quickly acute bouts of hyperinsulinemia can initiate the transition from a normal to insulin-resistant state. After only one-week of carbohydrate (fructose) overfeeding, fasting blood glucose 
c becomes elevated and symptoms of insulin resistance develop. ${ }^{7}$ However, following weight-loss in previously obese participants with type II diabetes, signs of insulinresistance persist and often weight-loss is not sustained. ${ }^{8}$ It is possible this imbalance reflects a genetic-predisposition favouring the development of insulin resistance but not the reverse.

\section{What's Old is New Again}

Although the AMDR is thought to protect from disease, it is worthwhile noting that 'diseases of civilization' are typically absent in hunter-gatherer societies. Total carbohydrate content of hunter-gatherer diets ${ }^{9,10}$ is significantly lower than both the AMDR and current consumption $(22-40 \%$ vs. $45-65 \%$ of total energy intake respectively). Huntergatherer diets are also notably devoid of refined grains and added sugars. ${ }^{10}$

Recently, the health benefits of a hunter-gatherer diet have been realized and used in a clinical setting to improve metabolic status. ${ }^{10}$ This should not be considered surprising as the carbohydrate provided by a hunter-gatherer diet closely aligns with the RDA and may be considered sufficient to support optimal health.

\section{Canadian Carbohydrate Considerations}

Canadians' carbohydrate consumption is estimated at $\sim 300 \mathrm{~g} /$ day. Although this intake closely aligns with the DRI-AMDR, ${ }^{2}$ it far exceeds what both human physiological requirements and modern day hunter-gatherer diets estimate are sufficient for healthy living., ${ }^{3,9}$ Of greatest concern, current carbohydrate intake too frequently consists of added sugars and processed foods, which can elicit hyperglycemic and hyperinsulinemic responses.

If Canada aims to improve health status, updated carbohydrate recommendations are necessary. These authors contend that carbohydrate recommendations more closely aligned with the DRI-RDA ( $130 \mathrm{~g} /$ day; or 20$40 \%$ of total calories) are a more appropriate target for optimal health. This level of intake appears to satisfy human biological requirement and is in agreement with our natural, ancestral eating patterns. To minimize unhealthy metabolic stress, nutritional recommendations must emphasize the consumption of unprocessed foods (vegetables, fruits, nuts, seeds, legumes and whole grains) at the expense of refined grains and added sugars.

\section{References}

1. Tjepkema M. Measured Obesity: Findings from the Canadian Community Health Survey: Measured Height and Weight. Ottawa, ON: Statistics Canada; 2005. 32p. Report No.: 82-620-MWE

2. Public Health Agency of Canada. Diabetes in Canada: Facts and figures from a public health perspective. Ottawa, ON: Public Health Agency of Canada; 2011. 112 p. Report No.: HP35-25/2011

3. Dietary Reference Intakes for Energy, Carbohydrate, Fiber, Fat, Fatty Acids, Cholesterol, Protein, and Amino Acids (Macronutrients). Washington, DC: The National Academies Press; 2005.

4. Harper AE. Defining the essentiality of nutrients. In: Shils MD, Olson JA, Shihe M, Ross AC, editors. Modern nutrition in health and disease. 9th ed. Boston. William and Wilkins; 1999.

5. Canada. Food Statistics. Ottawa, ON: Statistics Canada; 2009. 42 p. Report No.:21-020-X

6. Heaton KW, Marcus SN, Emmett PN, Bolton CH. Particle size of wheat, maize, and oat test meals: effects on plasma glucose and insulin responses and on the rate of starch digestion in vitro. Am J Clin Nutr 1988 Apr; 47(4): 675-682.

7. Faeh D, Minehira K, Schwarz J, Periasami R, Seongsu P, Tappy L. Effect of fructose overfeeding and fish oil administration on hepatic de novo lipogenesis and insulin sensitivity in healthy men. Diabetes. 2005 Jul; 54(7): 1907-1913.

8. Gumbiner B, Van Cauter E, Beltz WF, Ditzler TM, Griver K, Polonsky KS, et al. Abnormalities of insulin pulsatility and glucose oscillations during meals in obese noninsulin-dependent diabetic patients: effects of weight reduction. J Clin Endocrinol Metab. 1996 June 1; 81(6):2061-2068.

9. Cordain L, Miller JB, Eaton SB, Mann N, Holt SHA, Speth JD. Plant-animal subsistence ratios and macronutrient energy estimations in worldwide hunter-gatherer diets. Am J Clin Nutr 2000 Mar; 71(3):682-92.

10. Konner M, Boyd SB. Paleolithic Nutrition: Twenty-five years later. Nutr Clin Prac. 2010; 25(6): 594-602

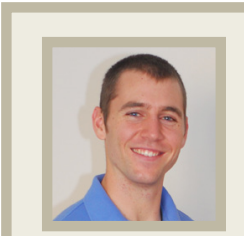

\section{T. Dylan Olver}

Combining the expertise of the Neurovascular Research and Exercise Biochemistry Labs from University of Western Ontario, Dylan's research investigates the role of acute and chronic alterations in glycemic status (glucose and insulin) on blood flow control.

\section{Graeme Thomas}

Working under the supervision of Dr. Peter WR Lemon chair of The Exercise Nutrition Research Lab at University of Western Ontario, Graeme's research focuses on developing health coaching software to compliment an 8-week fat loss program designed to improve body composition in various clinical populations. 